\title{
Efficacy of Early Mobilization on Bowel Motility For Children after Abdominal Surgery
}

\author{
Amany G. Abd-Elhamed ${ }^{1}$, Mohamed A. Osman ${ }^{2}$, Amal A. Mobarak ${ }^{3}$ \& Amal A. Hussien ${ }^{4}$. \\ 1. Assistant Lecturer in Pediatric Nursing Department, Faculty of Nursing, Assuit University, Egypt. \\ 2. Professor of Pediatric Surgery, Faculty of Medicine, Assuit University, Egypt. \\ 3. Assistant Professor of Pediatric Nursing, Faculty of Nursing, Assuit University, Egypt. \\ 4. Lecturer of Pediatric Nursing, Faculty of Nursing, Assiut University, Egypt.
}

\begin{abstract}
Early mobilization may exert a mechanical stimulation of intestinal function. Generally it is believed that early mobilization aids in the restoration of normal bowel function after abdominal surgery. Aim: this study aimed to determine the efficacy of early mobilization on bowel motility for children after abdominal surgery. Design: a quasi experimental research design was used to conduct this study. Subjects and method: a convenience sample of 60 children aged from 6 to 18 years. Setting: this study was conducted at the pediatric surgery unit in Assuit university children hospital. Tools: three tools were used to collect the necessary data, a structure questionnaire, child's mobilization and bowel motility monitoring sheet. Results: revealed that $(100 \%)$ of the studied group walked three time per day while only $(6.7 \%)$ in the control group during the post-operative day zero, time to passage of first flats and passage of first feces was statistically significant difference $\mathrm{P}=0.032 * \mathrm{P}=0.015 *$ respectively. Conclusion: the early mobilization had beneficial effect on early passage of flatus and feces in children after abdominal surgery. Recommendations: training educational program for the nurses about early mobilization after abdominal surgery, this study should be replicated and expanded to include a larger sample.
\end{abstract}

\section{Keywords: Abdominal surgery, Bowel motility, Children \& Early mobilization.}

\section{Introduction}

Abdominal surgery is a broad classification of surgical procedures performed in the abdominal region to diagnose or treat a medical condition. It involves different techniques depending on which abdominal organ is involved. Most of these procedures traditionally require opening the abdomen with a large incision and are referred to as open abdomen surgeries or laparotomies, which are considered as major operations. However, newer techniques have paved the way for laparoscopic surgeries that only require significantly smaller incisions that leave less scarring and cause less postoperative pain (Mcgrath \& Pomerantz, 2012).

Post-operative ileus is a major focus of concern for surgeons because it increases duration of hospitalization, cost of care and postoperative morbidity. Post-operative ileus is an absent or abnormal peristalsis after surgery causing a functional obstruction without mechanical blockage. A physiologic ileus can occur up to 72 hours after surgery (Venara et al., 2016).

Early mobilization is a widely practiced and important component of post-operative care following abdominal surgery. Its benefits were first reported in the 1940 when early mobilization was observed to hasten recovery, improve gastrointestinal, urinary tract function and reduce the incidence of post- operative pulmonary complications. Early mobilization include: moving in bed, sitting out of bed, standing, ambulating on the spot, hallway ambulation and low intensity exercise (Browning et al., 2011).

Once child is fully awake and has been given pain relief it is important to encourage him to mobilize (Thurston, 2013). Early ambulation is the most significant general nursing measure to prevent postoperative complications. Early mobilization of the post-operative patient reduces the catabolic effects of surgery on skeletal muscle, improves pulmonary functions and circulation through increased oxygen delivery to tissues and reduces the risk of venous thromboembolism. Post-operative ambulation promotes the return of gut function assisting in the prevention of postoperative ileus (Saleh $\&$ Majumbar, 2012).

It is role of the nurse to help children resolved early from post-operative ileus after abdominal surgery and assessed children for return of bowel motility (Lynee et al., 2013). Nurses use many non-pharmacologic treatment to enhance bowel motility such as early enteral nutrition, early mobilization, psychological pre-operative preparation and among them the use of chewing gum (Nimarta et al., 2013). 
During vital signs assessment, the nurse should exam abdomen and auscultate for bowel sound. Initially, bowel sounds are absent. As bowel motility resumes, bowel sounds gradually return. The child will begin to pass flatus or stool, and the abdomen will become softer and less distended. Serial measurements of abdominal girth are often useful in infants to track changes (Martin et al., 2013).

\section{Significance of the study}

Despite a number of advances in perioperative care and surgical techniques, post-operative ileus remains one of the commonest challenges in surgery and commonly seen following abdominal surgery. Postoperative ileus is an inevitable event after major abdominal surgery and it is considered the most important factor for prolonged hospital stay (Lubawski \& Saclarides 2008). It impacts greatly on children's recovery even after uncomplicated abdominal surgery and one of the commonest factors affecting healthcare costs in surgical children (Asgeirsson, 2010). Previous researchers found that early mobilization are from non-pharmacological methods that decrease post-operative ileus (Lafon \&Lawson, 2012). In spite of the importance of these methods, the researcher did not find valuable researches that had been carried out in our country (Egypt) and there is no researches in Egypt approved that. So, this study will be conducted to determine the efficacy of early mobilization on bowel motility for children after abdominal surgical ileus.

\section{Aim of the study}

This study aimed to determine the efficacy of early mobilization on bowel motility for children after abdominal surgery.

\section{Research hypotheses}

1. The first flatus and first bowel passed is earlier among children in study group compared to control group.

2. The length of post-operative hospital stay is lesser among children in study group compared to control group.

\section{Subjects \& Method \\ Research Design}

Quasi experimental research design was utilized in this study.

\section{Setting:}

This study was conducted at the pediatric surgery unit in Assiut university children hospital which served the Upper Egypt from Beni-Suef to Aswan.

Subjects

The study subjects were including a con venience sample of 60 children rom 6 to 18 years after abdominal surgery. They were divided randomly in to two groups with the same type of surgery:

Group I study group for early mobilization

Group II control group which mobilization and bowel motility were monitored without intervention while receiving routine hospital care.

\section{Inclusion Criteria included}

- Both sexes.

- Children aged 6-18 years according to (Jaimez, 2012).

- Children who were fully conscious, oriented and were able to follow instructions.

Exclusion Criteria included:

- Children refused to mobilize, unabled to walk or taken laxatives.

\section{Tools of data collection}

Three tools were used to collect the required data for this study:

Tool I: A structure questionnaire:

It was developed by the researcher to collect the required information and included three parts:

Part (1): Personal data of the studied children as (age and sex)

Part (2): Medical data related to child's surgery (types of abdominal surgery) according to surgical procerure open or laparoscopic and according to indication of abdominal surgery emergency or elective.

\section{Tool II: Child's mobilization}

It was developed by the researcher based on the study by (Fiore et al., 2017) and included the following: when the child dangled their legs, standed beside the bed and started to walk for the first time, duration of walking session and its frequency per day, total hours per day the child stayed outside the bed included sit in the chair.

\section{Tool III: Bowel motility monitoring}

It was developed by the researcher based on the study by (Jaimez, 2012) and was included the following information: Time to first flatus, first passage of stool, tolerate feedings (oral intake) and postoperative hospital stay.

\section{Method of data collection}

- Research proposal was approved from Ethical Committee in the faculty of Nursing.

- An official permission was obtained from the director of pediatric surgery unit in Assiut university children hospital to collect the necessary data for this study.

- Tool I, Tool II \& Tool III were developed by the researcher and were tested for its contents validity by 5 experts in both pediatric nursing and pediatric surgery fields and it was 0.96 for tool I, 0.98 for tool II and 0.97 for tool III. 
- The reliability of the tools was elicited by alpha Cronbach test and it was 0.862 for tool II and 0.841 for tool III.

Field of the work

This study was carried out through a period of seven months from the beginning of April (2018) to the end of October (2018).The researcher went to hospital five days per week, three times per day. The time needed for every child in the early mobilization group was difficult to estimate as it was different from child to another according to his tolerance to walk but it ranged from 15 minutes to 30 minutes. The time needed for every child in control group was 10 minutes for filling questionnaire sheet.

- Assessment of personal and medical data of children was done by the researcher by using tool I (part 1 and part 2) for the two groups.

\section{Intervention}

Early mobilization: In the study group started early mobilization a few hours after surgery by asking child to dangle their legs, stand at the bedside for a few minutes and then walk three times per day as (Aarts et al., 2013) did in their study. The child walks at least the length of hallway. Walking distance was increased according the child's tolerance and calculated by minutes using hand watch and it was recorded using tool II. This intervention was undertaken until POD 2 or hospital discharge, whichever came first. It was advisable for the children to be out of bed and sit in the chair for two hours the same day of the surgery and at least six hours a day on the following days until hospital discharge as (Fiore et al., 2017) and after the children were evaluated for their outcomes using tool III.

The control group: control group in which mobilization and bowel motility were monitored without any intervention the children were visited three times per day to monitor their mobilization and fulfill bowel motility monitoring sheet using tool II \& III.

\section{Ethical Consideration}

The ethical research consideration in this study includes the following:

- Research proposal was approved from Ethical Committee in the Faculty of Nursing.

- There was no risk for study subject during application of the research.

- The study was following common ethical principles in clinical research.

- Written consent was obtained from parents that are willing to participate in the study, after explaining the nature and purpose the study.

- Parents were assured that the data of this research will not be reused without second permission.

- Confidentiality and anonymity was assured.

- Parents and children had the right to refuse participation and or withdraw from the study without any rational any time.

\section{Pilot study}

Apilot study was carried out on $10 \%$ of children to test the clarity and applicability of the sheet and to estimate time needed to fulfill each sheet. There was no modification done so, the children were included in the total sample of the study.

\section{Statistical analysis}

Data entry and data analysis were done by using SPSS program (Statistical Package for Social Science) version 20. Data were presented as number, percentage, mean and standard deviation. Chi- square test and fisher exact test were used to compare qualitative data and independent T-test used to compare quantitative data. P-value considered statistically significant when $\mathrm{p}<0.05$.

\section{Results}

Table (1): Percentage distribution of studied children regarding their personal data.

\begin{tabular}{|c|c|c|c|c|c|}
\hline \multirow{2}{*}{ Personal data } & \multicolumn{2}{|c|}{ Study group $(n=30)$} & \multicolumn{2}{|c|}{ Control group $(n=30)$} & \multirow{2}{*}{ P-value } \\
\hline & No. & $\%$ & No. & $\%$ & \\
\hline \multicolumn{5}{|l|}{ Child's age / years } & \multirow{5}{*}{0.109} \\
\hline $6-<9$ yrs & 9 & 30.0 & 10 & 33.3 & \\
\hline $9-<12$ yrs & 8 & 26.7 & 10 & 33.3 & \\
\hline $12-<15$ yrs & 9 & 30.0 & 2 & 6.7 & \\
\hline $15-18$ yrs & 4 & 13.3 & 8 & 26.7 & \\
\hline Range & \multicolumn{2}{|c|}{$6.0-17.0$} & \multicolumn{2}{|c|}{$6.0-17.0$} & \multirow{2}{*}{0.508} \\
\hline Mean \pm SD & \multicolumn{2}{|c|}{$10.80 \pm 3.24$} & \multicolumn{2}{|c|}{$10.57 \pm 3.72$} & \\
\hline \multicolumn{5}{|l|}{\begin{tabular}{|l|} 
Child's sex \\
\end{tabular}} & \multirow{3}{*}{0.196} \\
\hline Male & 13 & 43.3 & 18 & 60.0 & \\
\hline Female & 17 & 56.7 & 12 & 40.0 & \\
\hline
\end{tabular}


Table (2): Percentage distribution of studied children regarding types of abdominal surgery.

\begin{tabular}{|c|c|c|c|c|}
\hline \multirow[t]{2}{*}{ Types of abdominal surgery } & \multicolumn{2}{|c|}{$\begin{array}{c}\text { Study group } \\
\quad(\mathbf{n}=\mathbf{3 0})\end{array}$} & \multicolumn{2}{|c|}{$\begin{array}{c}\text { Control group } \\
(n=\mathbf{3 0})\end{array}$} \\
\hline & No. & $\%$ & No. & $\%$ \\
\hline \multicolumn{5}{|l|}{ Type of surgical procedure: } \\
\hline Open & 28 & 93.3 & 28 & 93.3 \\
\hline Laparoscopic & 2 & 6.7 & 2 & 6.7 \\
\hline \multicolumn{5}{|l|}{ Indication of abdominal surgery: } \\
\hline Emergency abdominal surgery & 18 & 60.0 & 18 & 60.0 \\
\hline $\begin{array}{l}\text { Laparotomy peritoneal } \\
\text { lavage \& appendectomy }\end{array}$ & 10 & 33.3 & 10 & 33.3 \\
\hline Appendectomy & 8 & 26.7 & 8 & 26.7 \\
\hline Elective abdominal surgery & 12 & 40.0 & 12 & 40.0 \\
\hline Exploration & 5 & 16.6 & 5 & 16.6 \\
\hline Splenectomy & 3 & 10.0 & 3 & 10.0 \\
\hline Cholecystectomy & 2 & 6.7 & 2 & 6.7 \\
\hline Closure of intestinal stoma & 2 & 6.7 & 2 & 6.7 \\
\hline
\end{tabular}

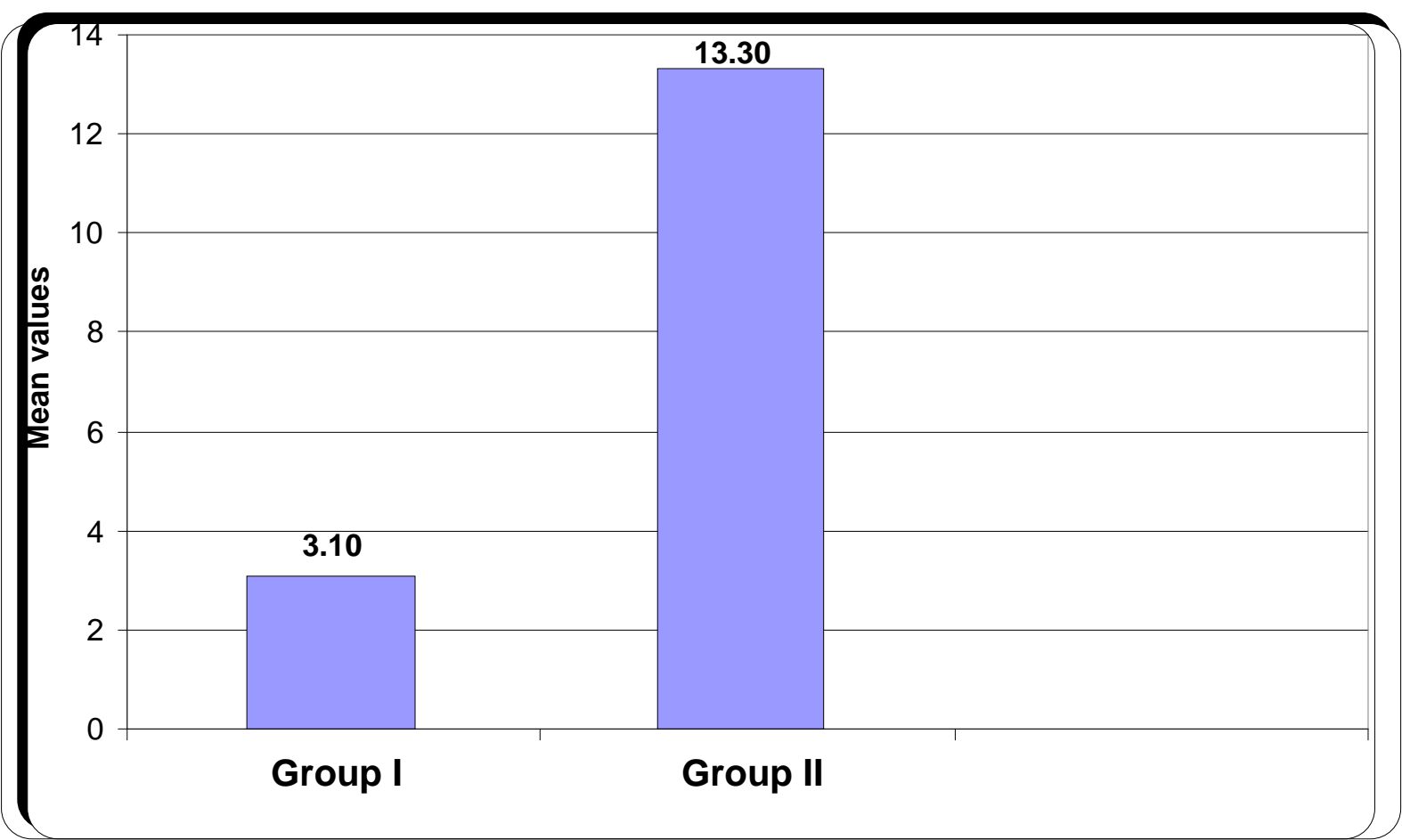

Figure (1): The mean time of starting mobilization after abdominal surgery in hours. 
Table (3): Frequency of walking sessions for the studied children and its' duration in minutes on the postoperative day zero (POD 0).

\begin{tabular}{|c|c|c|c|c|c|}
\hline \multirow{2}{*}{ Walking sessions } & \multicolumn{2}{|c|}{ Study group $(n=30)$} & \multicolumn{2}{|c|}{ Control group $(n=30)$} & \multirow{2}{*}{ P-value } \\
\hline & No. & $\%$ & No. & $\%$ & \\
\hline \multicolumn{6}{|c|}{ Frequency of walking sessions/ day } \\
\hline No walking & 0 & 0.0 & 11 & 36.7 & $0.000^{*}$ \\
\hline First & 30 & 100.0 & 19 & 63.3 & $0.000 *$ \\
\hline Second & 30 & 100.0 & 9 & 30.0 & $0.000 *$ \\
\hline Third & 30 & 100.0 & 2 & 6.7 & $0.000 *$ \\
\hline \multicolumn{5}{|c|}{ Duration of first walk/ minutes } & \multirow{3}{*}{0.183} \\
\hline Range & \multirow{2}{*}{\multicolumn{2}{|c|}{$\begin{array}{c}5.0-12.0 \\
7.13 \pm 1.83\end{array}$}} & \multicolumn{2}{|c|}{$2.0-10.0$} & \\
\hline Mean \pm SD & & & & 2.69 & \\
\hline \multicolumn{5}{|l|}{ Help: } & \multirow{3}{*}{--} \\
\hline With & 30 & 100.0 & 19 & 100.0 & \\
\hline Without & 0 & 0.0 & 0 & 0.0 & \\
\hline \multicolumn{5}{|c|}{ Duration of second walk/ minutes } & \multirow{3}{*}{0.255} \\
\hline Range & & & & 0.0 & \\
\hline Mean \pm SD & 8.9 & .23 & & 1.77 & \\
\hline \multicolumn{5}{|l|}{ Help: } & \multirow{3}{*}{1.000} \\
\hline With & 22 & 73.3 & 7 & 77.8 & \\
\hline Without & 8 & 26.7 & 2 & 22.2 & \\
\hline \multicolumn{5}{|c|}{ Duration of third walk/ minutes } & \multirow{3}{*}{$0.041 *$} \\
\hline Range & & & & 0.0 & \\
\hline Mean \pm SD & 9.6 & .43 & & 3.54 & \\
\hline \multicolumn{5}{|l|}{ Help: } & \multirow{3}{*}{1.000} \\
\hline With & 13 & 43.3 & 1 & 50.0 & \\
\hline Without & 17 & 56.7 & 1 & 50.0 & \\
\hline
\end{tabular}

Table (4): Frequency of walking sessions for the studied children and its' duration in minutes on postoperative day one (POD 1).

\begin{tabular}{|c|c|c|c|c|c|}
\hline \multirow{2}{*}{ Walking sessions } & \multicolumn{2}{|c|}{ Study group $(n=30)$} & \multicolumn{2}{|c|}{ Control group $(n=30)$} & \multirow{2}{*}{ P-value } \\
\hline & No. & $\%$ & No. & $\%$ & \\
\hline \multicolumn{6}{|c|}{ Frequency of walking sessions / day } \\
\hline First & 30 & 100.0 & 30 & 100.0 & -- \\
\hline Second & 30 & 100.0 & 26 & 86.7 & 0.112 \\
\hline Third & 30 & 100.0 & 16 & 53.3 & $0.000 *$ \\
\hline \multicolumn{5}{|c|}{ Duration of first walk/ minutes } & \multirow{3}{*}{$0.001^{*}$} \\
\hline Range & & 15.0 & & 15.0 & \\
\hline Mean \pm SD & & +2.60 & & 2.78 & \\
\hline \multicolumn{5}{|l|}{ Help: } & \multirow{3}{*}{$0.000^{*}$} \\
\hline With & 7 & 23.3 & 21 & 70.0 & \\
\hline Without & 23 & 76.7 & 9 & 30.0 & \\
\hline \multicolumn{5}{|c|}{ Duration of second walk/ minutes } & \multirow{3}{*}{$0.001 *$} \\
\hline Range & & 20.0 & & 15.0 & \\
\hline Mean \pm SD & & \pm 3.02 & & 3.06 & \\
\hline \multicolumn{5}{|l|}{ Help: } & \multirow{3}{*}{0.213} \\
\hline With & 5 & 16.7 & 8 & 30.8 & \\
\hline Without & 25 & 83.3 & 18 & 69.2 & \\
\hline
\end{tabular}




\begin{tabular}{|c|c|c|c|c|c|}
\hline \multirow{2}{*}{ Walking sessions } & \multicolumn{2}{|c|}{ Study group $(n=30)$} & \multicolumn{2}{|c|}{ Control group $(n=30)$} & \multirow{2}{*}{ P-value } \\
\hline & No. & $\%$ & No. & $\%$ & \\
\hline \multicolumn{5}{|c|}{ Duration of third walk/ minutes } & \multirow{3}{*}{0.229} \\
\hline Range & \multicolumn{2}{|c|}{$6.0-20.0$} & \multicolumn{2}{|c|}{$5.0-15.0$} & \\
\hline Mean \pm SD & \multicolumn{2}{|c|}{$13.20 \pm 2.86$} & \multicolumn{2}{|c|}{$11.88 \pm 3.10$} & \\
\hline \multicolumn{5}{|l|}{ Help: } & \multirow{3}{*}{1.000} \\
\hline With & 2 & 6.7 & 1 & 6.3 & \\
\hline Without & 28 & 93.3 & 15 & 93.8 & \\
\hline
\end{tabular}

Table (5): Frequency of walking sessions for the studied children and its' duration in minutes on postoperative day two (POD 2).

\begin{tabular}{|c|c|c|c|c|c|}
\hline \multirow[t]{2}{*}{ Walking sessions } & \multicolumn{2}{|c|}{$\begin{array}{c}\text { Study group } \\
(\mathrm{n}=22)\end{array}$} & \multicolumn{2}{|c|}{$\begin{array}{c}\text { Control group } \\
(n=28)\end{array}$} & \multirow[t]{2}{*}{ P-value } \\
\hline & No. & $\%$ & No. & $\%$ & \\
\hline \multicolumn{6}{|c|}{ Frequency of walking sessions/ day } \\
\hline First & 22 & 100.0 & 28 & 100.0 & -- \\
\hline Second & 22 & 100.0 & 27 & 90.0 & 1.000 \\
\hline Third & 22 & 100.0 & 22 & 78.6 & $0.028 *$ \\
\hline \multicolumn{5}{|c|}{ Duration of first walk/ minutes } & \multirow{3}{*}{$0.000^{*}$} \\
\hline Range & \multicolumn{2}{|c|}{$7.0-16.0$} & \multicolumn{2}{|c|}{$5.0-15.0$} & \\
\hline Mean \pm SD & \multicolumn{2}{|c|}{$13.09 \pm 2.69$} & \multicolumn{2}{|c|}{$9.04 \pm 2.91$} & \\
\hline \multicolumn{5}{|l|}{ Help: } & \multirow{3}{*}{0.246} \\
\hline With & 0 & 0.0 & 3 & 10.7 & \\
\hline Without & 22 & 100.0 & 25 & 89.3 & \\
\hline \multicolumn{5}{|c|}{ Duration of second walk/ minutes } & \multirow{3}{*}{$0.000 *$} \\
\hline Range & \multicolumn{2}{|c|}{$8.0-17.0$} & \multicolumn{2}{|c|}{$5.0-15.0$} & \\
\hline Mean \pm SD & \multicolumn{2}{|c|}{$14.14 \pm 2.44$} & \multicolumn{2}{|c|}{$10.56 \pm 2.53$} & \\
\hline \multicolumn{5}{|l|}{ Help: } & \multirow{3}{*}{0.495} \\
\hline With & 0 & 0.0 & 2 & 7.4 & \\
\hline Without & 22 & 100.0 & 25 & 92.6 & \\
\hline \multicolumn{5}{|c|}{ Duration of third walk/ minutes } & \multirow{3}{*}{$0.000 *$} \\
\hline Range & \multicolumn{2}{|c|}{$10.0-20.0$} & \multicolumn{2}{|c|}{$5.0-15.0$} & \\
\hline Mean \pm SD & \multicolumn{2}{|c|}{$15.32 \pm 2.55$} & \multicolumn{2}{|c|}{$11.82 \pm 2.91$} & \\
\hline \multicolumn{5}{|l|}{ Help: } & \multirow{3}{*}{1.000} \\
\hline With & 0 & 0.0 & 1 & 4.5 & \\
\hline Without & 22 & 100.0 & 21 & 95.5 & \\
\hline
\end{tabular}

N.B: Study group: (8 discharg)

Control group: (2 discharge) 


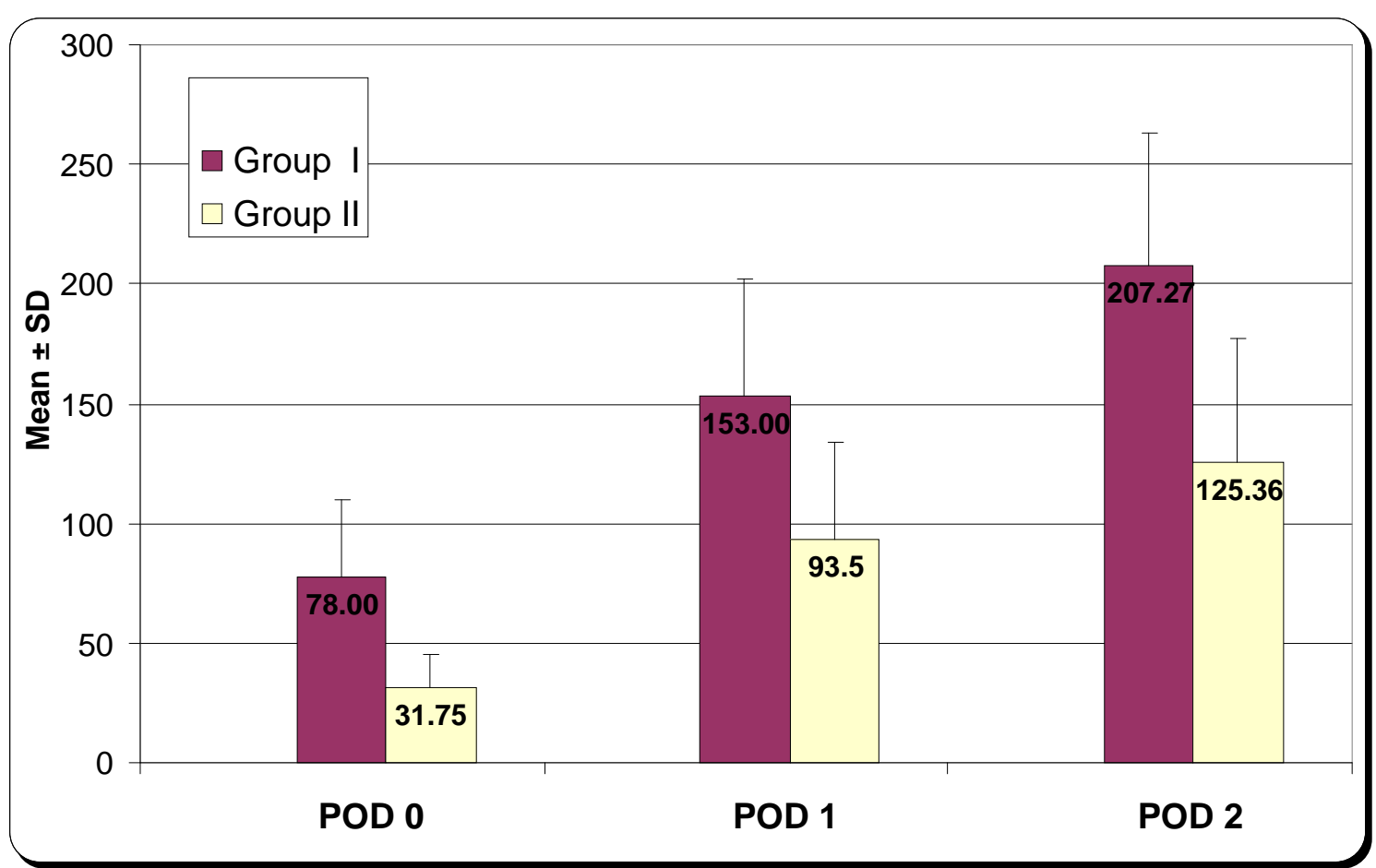

Figure (2): The mean duration of staying outside the bed in minutes

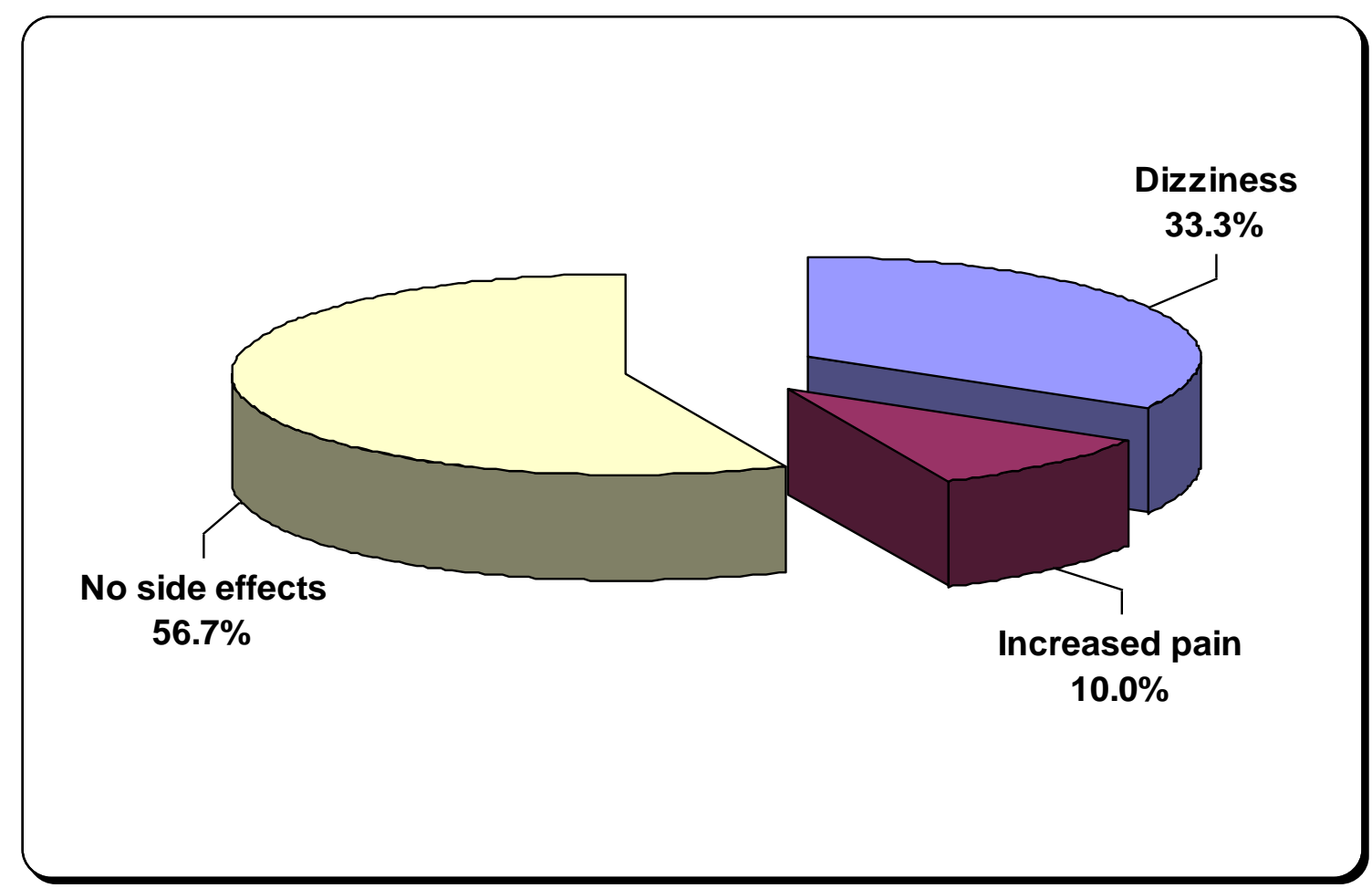

Figure (3): Early mobilization side effects for study group. 
Table (6): Efficacy of early mobilization on bowel motility for children after abdominal surgery.

\begin{tabular}{|c|c|c|c|c|c|}
\hline \multirow{2}{*}{ Early mobilization / bowel motility } & \multicolumn{2}{|c|}{$\begin{array}{c}\text { Study group } \\
(\mathrm{n}=\mathbf{3 0})\end{array}$} & \multicolumn{2}{|c|}{$\begin{array}{c}\text { Control group } \\
(n=30)\end{array}$} & \multirow{2}{*}{ P-value } \\
\hline & No. & $\%$ & No. & $\%$ & \\
\hline \multicolumn{5}{|l|}{ Return of bowel sound/ hours } & \multirow{4}{*}{0.166} \\
\hline$<12 \mathrm{hrs}$ & 10 & 33.3 & 7 & 23.3 & \\
\hline $12-<24 \mathrm{hrs}$ & 13 & 43.3 & 9 & 30.0 & \\
\hline$\geq 24 \mathrm{hrs}$ & 7 & 23.3 & 14 & 46.7 & \\
\hline \multicolumn{5}{|l|}{ Passage of first flatus/ hours } & \multirow{4}{*}{$0.032 *$} \\
\hline$<12 \mathrm{hrs}$ & 8 & 26.7 & 3 & 10.0 & \\
\hline $12-<24 \mathrm{hrs}$ & 10 & 33.3 & 5 & 16.7 & \\
\hline$\geq 24 \mathrm{hrs}$ & 12 & 40.0 & 22 & 73.3 & \\
\hline \multicolumn{5}{|l|}{ Passage of first feces/ hours } & \multirow{4}{*}{$0.015 *$} \\
\hline$<24 \mathrm{hrs}$ & 8 & 26.7 & 5 & 16.7 & \\
\hline $24-48 \mathrm{hrs}$ & 14 & 46.7 & 6 & 20.0 & \\
\hline$>48 \mathrm{hrs}$ & 8 & 26.7 & 19 & 63.3 & \\
\hline \multicolumn{5}{|l|}{ Return of appetite/ hours } & \multirow{4}{*}{0.271} \\
\hline$<24 \mathrm{hrs}$ & 14 & 46.7 & 8 & 26.7 & \\
\hline $24-48$ hrs & 12 & 40.0 & 16 & 53.3 & \\
\hline$>48 \mathrm{hrs}$ & 4 & 13.3 & 6 & 20.0 & \\
\hline \multicolumn{5}{|l|}{ Time of liquid diet/ hours } & \multirow{5}{*}{0.080} \\
\hline$<12 \mathrm{hrs}$ & 6 & 20.0 & 1 & 3.3 & \\
\hline $12-<24 \mathrm{hrs}$ & 10 & 33.3 & 6 & 20.0 & \\
\hline $24-48 \mathrm{hrs}$ & 9 & 30.0 & 15 & 50.0 & \\
\hline$>48 \mathrm{hrs}$ & 5 & 16.7 & 8 & 26.7 & \\
\hline \multicolumn{5}{|l|}{ Time of soft diet/ hours } & \multirow{4}{*}{0.481} \\
\hline$<24 \mathrm{hrs}$ & 5 & 16.7 & 2 & 6.7 & \\
\hline $24-48 \mathrm{hrs}$ & 14 & 46.7 & 16 & 53.3 & \\
\hline$>48 \mathrm{hrs}$ & 11 & 36.7 & 12 & 40.0 & \\
\hline \multicolumn{5}{|l|}{ Time of regular diet/ days } & \multirow{4}{*}{0.053} \\
\hline$<2$ days & 8 & 26.7 & 3 & 10.0 & \\
\hline 2-3 days & 12 & 40.0 & 8 & 26.7 & \\
\hline$>3$ days & 10 & 33.3 & 19 & 63.3 & \\
\hline
\end{tabular}

$P$-value significant $<0.05$

$P$-value not significant $\geq 0.05$

Table (7): Efficacy of early mobilization on post-operative hospital stay.

\begin{tabular}{|l|c|c|c|c|c|}
\hline \multirow{2}{*}{ Early mobilization/ hospital stay } & \multicolumn{2}{|c|}{$\begin{array}{c}\text { Study group } \\
(\mathbf{n = 3 0})\end{array}$} & \multicolumn{2}{c|}{$\begin{array}{c}\text { Control group } \\
(\mathbf{n = 3 0})\end{array}$} & \multirow{2}{*}{ P-value } \\
\cline { 2 - 5 } & No. & $\mathbf{\%}$ & No. & \% & \\
\hline Post-operative hospital stay/ days & & & & & \\
\hline$<2$ days & 8 & 26.7 & 2 & 6.7 & \multirow{2}{*}{0.206} \\
\hline 2-<4 days & 10 & 33.3 & 11 & 36.7 & \\
\hline 4-7 days & 9 & 30.0 & 12 & 40.0 & \\
\hline$>7$ days & 3 & 10.0 & 5 & 16.7 & \\
\hline
\end{tabular}

P-value significant $<0.05$

$P$-value not significant $\geq 0.05$

Table (1): Shows percentage distribution of studied children regarding their personal data. Findings revealed more than half $(56.7 \%)$ was female in the study group while $(40 \%)$ was female in control group. Regarding child's age group more than one quarter $(30 \%)$ was from $(6-<9$ years $) \&(12-<15$ years) in the study group while about one third $(33.3 \%)$ in control group was in age group from (6 -< 9 years) $\&(9-<12$ years $)$ and these differences were not statistically significant $\mathrm{p}$-value $=0.206$. 
Table (2): Represents percentage distribution of studied children regarding types of abdominal surgery. It was noted that the majority of surgical procedure of studied children $(93.3 \%)$ was open in the two groups. More than half $(60 \%)$ of abdominal surgery was emergency and $(40 \%)$ was elective surgery in the two groups. It was noted that one third $(33.3 \%)$ of the emergency surgery was laparotomy peritoneal lavage $\&$ appendectomy while $(16.6 \%)$ of the elective surgery was exploration in the two groups.

Figure (1): Shows the mean duration of starting mobilization after abdominal surgery in hours. It was noted that the mean duration of starting mobilization was shorter in the study group than the control group.

Table (3): Illustrates frequency of walking sessions for the studied children and its' duration in minutes on the post-operative day zero (POD 0). Regarding frequency of walking it was noted that on the study group $(100 \%)$ of the studied children walked three times while only $(6.7 \%)$ of the control group walked three times per day and there were statistically significant difference between study and control groups $p$-value $=0.000^{*}$. Also it was found that there were statistically significant difference between study group and control group on the duration of third walk p-value $=0.041^{*}$.

Table (4): Illustrates frequency of walking sessions for the studied children and its' duration in minutes on post-operative day one (POD 1). Regarding frequency of walking at third time it was noticed that $(100 \%)$ of the studied group walked three time per day while $(53.3 \%)$ of the control group walked three time per day and there were statistically significant difference between study group and control $\mathrm{p}$-value $=$ $0.000 *$. Also it was found that there were statistically significant difference between study group and control group on the duration of first walk $\mathrm{p}$-value $=$ $0.000^{*}$.

Table (5): Shows frequency of walking sessions for the studied children and its' duration in minutes on post-operative day two (POD 2). Regarding frequency of walking at third time it was noticed that there were statistically significance difference between study group and control group pvalue $=0.028^{*}$. Also it was found that there were statistically significant difference between study group and control group on the duration of first, second and third walk $\mathrm{p}$-value $=0.000^{*}$.

Figure (2): Presents the mean duration of staying outside the bed in minutes. It was noted that the mean duration of staying outside the bed was longer in the early mobilization group than the control group on the post-operative day zero, POD $1 \&$ POD 2.
Figure (3): Demonstrates early mobilization side effects. It was noted that $(56.7 \%)$ of the studied children had no side effects while $(10 \%)$ of them suffer from increasing pain

Table (6): Presents efficacy of early mobilization on bowel motility for children after abdominal surgery. It was found that that there were statistically significant difference between study group and control regarding passage of first flatus and passage of first feces $p$-value $=0.032^{*}$ p-value $=0.015^{*}$ respectively. while there were no statistically significant difference between study group and control group regarding return of bowel sound, return of appetite, time of liquid diet, time of soft diet and time of liquid diet.

Table (7): Presents efficacy of early mobilization on post-operative hospital stay. It was noticed that there was no statistically significant difference between study group and control group.

\section{Discussion}

Early mobilization improves circulation, accelerates peristalsis and lowers postoperative abdominal distention by increasing abdominal wall tonus and gastrointestinal system functions. Early ambulation aids in the restoration of normal bowel function, allows patients to more easily pass flatus and stool, and resume normal bowel habits. Patients are encouraged to walk for their overall well-being but also in an effort to resolve more quickly ileus and to relieve the associated cramps and bloating (Malik et al., 2013).

Regarding the time of starting mobilization after abdominal surgery in hours, early mobilization group start to mobilize earlier than the control group and the difference was statistically significant. These finding was go on line with Fiore et al., (2017) in their study about ensuring early mobilization within an enhanced recovery program for colorectal surgery who found that study group start to mobilize earlier than the control group.

As regard frequency of walking on the post-operative day zero, one and two, the frequency of walking in the early mobilization group was more than the control group and the difference was statistically significant and these finding was in agreement with Burt \& Vinay, (2017) in their study about the role of ambulation in the treatment of postoperative ileus who found that study group enforced to walk so, their frequency of walking was more than the control group.

In the present study, the duration of walking was longer in the early mobilization group than the control group and the difference was statistically significant and these finding was in agreement with 
Fiore et al., (2017) in their study about ensuring early mobilization within an enhanced recovery program for colorectal surgery who reported that the facilitated mobilization group, adherence to mobilization targets was greater on POD0, POD1, POD2 and there were statistically significant difference regarding walking duration.

Regarding duration of staying outside the bed in minutes. The finding of the present study was revealed that early mobilization group stayed longer time outside the bed than the control group. These finding was go on line with Basseet al., (2002) who found that the interventional group's who received multimodal rehabilitation program total time out of bed was significantly longer than that of the control group.

In the present study, it was found that more than half of the early mobilization group reported no side effects from early mobilization, one third of them felt dizziness and miniority felt increased pain. These finding was similar to Reismann et al., (2009) who investigated the feasibility of "fast-track" concepts in pediatric patients, with appendectomy and other surgical procedures. The fast-track concept included immediate mobilization among other interventions. Mobilization occurred at only 2 hours postoperatively and no complications were identified. The researchers concluded that fast-track concepts and quick mobilization in the postoperative period can be safely applied to children.

Regarding efficacy of early mobilization on bowel motility for children after abdominal surgery. It was assessed by return of bowel sound, passage of first flatus, passage of first feces, return of appetite, time of liquid diet, time of soft diet and time of regular diet.

In the present study, it was found that return of bowel sound was earlier in early mobilization group but the difference was not statistically significant. These finding was go on line with John et al., (1990) in their study about the effect of ambulation on recovery from postoperative ileus who found that ambulation appears to have no overall effect on promoting an early recovery of normal gastrointestinal myoelectric activity.

As regard passage of first flatus, it was earlier in the early mobilization group and the difference was statistically significant as stated in this study first hypothesis. These finding was similar to Yuan et al., (2018) in their study about enhanced recovery program in liver resection surgery who reported that time to first flatus after surgery was significantly shorter in the ERAS group than in the control group. In the present study, passage of first feces was earlier in the early mobilization group and the difference was statistically significant as stated in this study second hyopthesis. These finding was in agreement with Raue et al., (2004) who researched whether a "Fast-Track" multimodal rehabilitation program improved outcomes after laparoscopic sigmoidectomy. The fast track multimodal group was out of bed on day 0 of surgery and for extended lengths beginning on day 1 post-operatively. Fast track patients had bowel movements 1 day earlier than the control group, also Leonard, (2018) found that going for short walks around the hospital after surgery will help move food through the intestines and stimulate a bowel movement.

Regarding return of appetite, time of liquid diet, time of soft diet and time of regular diet, it was earlier in the early mobilization group than the control group but the difference was not statistically significant as stated in this study third hypothesis. These finding was in agreement with Rothman et al., (2016) in their study about the impact of early ambulation in the pediatric postoperative appendectomy who reported that return appetite and start feeding was earlier in the study group but there was no statistically significant difference.

Regarding efficacy of early mobilization on postoperative hospital stay. It was noticed that there was no statistically significant difference between early mobilization group and control group as stated in this study fourth hypothesis. These finding congruent with Robert \& Massey, (2010) who found that early mobilization had no effect on time to discharge but disagreement with (Rothman et al., 2016) who found early ambulation has a significant impact on length of stay.

\section{Conclusion}

Based on the results of the present study, it concluded that early mobilization had statistically significant effect on passage of first flatus and passage of first feces but had no statistically significant effect on return of bowel sound, return of appetite, time of liquid diet and time of soft diet.

\section{Recommendations}

Based on the results of the current study, the

following recommendations are suggested:

1. Training educational program for the nurses about early mobilization after abdominal surgery and its' benefits.

2. Early mobilization should be enforced by care giver for the over well being of the patient.

3. This study should be replicated and expanded to include a larger sample, focusing on outcomes with different children populations undergoing a variety of abdominal surgery. 


\section{References}

1. Aarts M., Okrainec A.,Wood T., Pearsall E., \& Mcleod R., (2013): Enhanced Recovery after Surgery Guideline. ERAS, 600 University Ave, Pp: 449.

2. Asgeirsson T., (2010): Postoperative ileus it costs more than you expect. J Am Coll Surg, 210(2), Pp:228-31.

3. Basse L., Raskov H., Hjort J., Sonne E., Billesbolle P., Hendel H., \& Kehlet H., (2002): Accelerated postoperative recovery programme after colonic resection improves physical performance, pulmonary function and body composition. British Journal of Surgery, 89, Pp: 446-53.

4. Burt C., \&Vinay K., (2017): What is the role of ambulation in the treatment of postoperative ileu? Medscape nurses available at www.medscape.com/answers/224214169274/what-is-the-role-of-ambulation-in-thetreatment-of-postoperative-ileus

5. Fiore J., Castelino T., Pecorelli N., Niculiseanu P., Balvardi S., Hreshorn O., Liberman S., Chalebois P., Stein B., Carli F., Mayo N., \& Feldman L., (2017): Ensuring early mobilization within an enhanced recovery program for colorectal surgery. Ann Surg. 266 (2), Pp: 231-33.

6. Jaimez G., (2012): Chewing Gum Use to Reduce Post-operative Ileus in Pediatric Patients. Clinical Trials.g available at: https://clinicaltrials.gov

7. John H., Waldhausen T., \& Bruc E., (1990): The effect of ambulation on recovery from postoperative ileus. Ann. Surg., 212(6), Pp: 671-77.

8. Lafon C., \& Lawson L., (2012): Gum Chewing As a Strategy To Reduce The Duration Of Postoperative Ileus. Gastrointestinal Nursing, 10(3), Pp:17-22.

9. Browning L., Denehy L., \& Scholes R., (2011): The quality of early upright mobilization performed following upper abdominal surgery is low: an observationalstudy.Availablefrom:http://www.ncbi. nlm.nih.govt/pubmed/21141230

10. Leonard J., (2018): What to know about constipation after surgery. Medical news today available at: https://www.medicalnewstoday.com/articles/32326 4.php

11. Lubawski J., \& Saclarides T., (2008): Postoperative ileus: strategies for reduction. Ther Clin Risk Manag., 4(5), Pp:913-7.

12. Lynee D., Browne N., Flanigan L. ,\& Pieper P., (2013): Nursing Care of Pediatric Surgical Patient, $3^{\text {rd }}$ ed., United States of America, Ascend learning company, chapter 7: enteral route of nutrition, $\mathrm{Pp}$ : 103
13. Malik A., Khurshid S., Chowdhri N., \& Parray F., (2013): Enhanced Recovery after Surgery (ERAS) in Patients Undergoing Colorectal Surgeries. International Journal of Surgical Research, 2(5), Pp :5762.

14. Martin S., Kerr C., \& Hazinski M., (2013): Nursing Care of Critically Ill Child, $3^{\text {rd }}$ ed., United States of America, Elsevier Mosby, Chapter 14: Gastrointestinal and Nutritional Disorders, Pp: 800801.

15. Mcgrath M., \& Pomerantz J., (2012): Sabiston Textbook of Surgery, $19^{\text {th }}$ ed., Philadelphia, Elsevier Saunders, chapter 69: Plastic surgery, Pp.: 1932-33.

16. Nimarta S., Neena V., \& Gupta R., (2013): Effectiveness of chewing gum on bowel motility among the patients who have undergone abdominal surgery. Nursing and midwifery Research Journal, 9 (3), Pp.: 108-12.

17. Raue W., Haase O., Jinghans T., Schafenberg M., Muller J., \& Schwenk W., (2004): "FastTrack" multimodal rehabiliation program improves outcome after laparoscopic sigmoidectomy. Surgical Endoscopy, 18, Pp: 1463-68.

18. Reismann M., Dingemann J., Wolters M., Laupichler B., Suempelmann R., \& Ure B., (2009): Fast-track concepts in routine pediatric surgery: A prospective study in 436 infants and children. Langenbeck's Archives of Surgery, 394, Pp: 529-33.

19. Robert L., \& Massey P., (2010): A randomized trial of rocking-chair motion on the effect of postoperative ileus duration in patients with cancer recovering from abdominal surgery. Applied Nursing Research, 23 (2): 59-64.

20. Rothman K., Garvanc C., \& Neu M., (2016): The impact of early ambulation in the pediatric postoperative appendectomy. Journal of pediatric surgical nursing, 5(3), Pp: 70-75.

21. Saleh S., \& Majumbar A., (2012): Innovations in the care of postoperative hysterectomy patients. In A. Al-Hendy \& M. Sabry (Eds.), Hysterectomy, Pp: 251-68.

22. Thurston C., (2013): Essential Nursing Care For Children and Young People, New-York, Routledge, chapter 8: Caring for Children and Young people in Surgical Setting, Pp: 185.

23. Venara A., Neunlist M., Slim K., Barbieux J., Colas P., Hamy A., \& Meurette G., (2016): Postoperative ileus: Pathophysiology, incidence, and prevention. Journal of Visceral Surgery, 153 (6), Pp: 439-46.

24. Yuan D., Zhenzhen G., \& Zhongquan S., (2018): Enhanced recovery program in liver resection surgery. Translational cancer research, 7(4). 